\title{
PENGARUH TERAPI MURATTAL AL-QURAN TERHADAP KECEMASAN PADA PEKERJA LAYANAN JASA BOGA DI KABUPATEN CIREBON PADA ERA PANDEMI COVID 19 TAHUN 2020.
}

\author{
Rachmat Roebidin, Mamlukah, Rossi Suparman, Esty Febriani \\ STIKes Kuningan \\ rachmatroebidin6782@gmail.com
}

\begin{abstract}
Abstrak
Terapi Murottal al-Quran adalah terapi mendengarkan bacaan al-Quran yang merupakan terapi religi bahwa seseorang dibacakan ayat-ayat al-Quran selama beberapa menit atau jam sehingga memberikan dampak positif. Penyebaran pandemi Covid 19 secara cepat dan luas mengakibat perubahan signifikan pada segala aspek kehidupan masyarakat, pandemi psikologi Covid 19 telah menyebarkan ketakutan, kecemasan dan kepanikan secara cepat di seluruh dunia. Dampak tersebut juga dialami oleh pekerja layanan jasa boga. Oleh karena itu perlu diberikan intervensi berupa terapi Murottal al-Quran agar dapat menurunkan tingkat kecemasan. Adakah pengaruh terapi Murattal al-Quran terhadap kecemasan, pada pekerja layanan jasa boga di Kabupaten Cirebon Pada Era Pandemi Covid 19 Tahun 2020. Penelitian quasi experimental dan rancangan pre and posttest with control group design. Jumlah populasi 64 responden dengan sampel 30 kasus dan 30 kontrol dengan metode purposive sampling dan pengambilan data menggunakan Hamilton Anxiety Rating Scale (HARS). Didapatkan jumlah responden yang mengalami kecemasan berat sebanyak (66,6\%). Pengaruh terapi Murattal alQuran terhadap kecemasan $\mathrm{p}$ value $=0,000$ Kesimpulannya terdapat pengaruh terapi Murattal al-Quran terhadap kecemasan.
\end{abstract}

Kata Kunci : Terapi Murottal al-Quran, Kecemasan

\section{Pendahuluan}

Tingkat kelelahan akibat kerja yang dialami pekerja dapat menyebabkan ketidaknyamanan, salah satu ketidaknyamanan yang dialami oleh pekerja adalah kecemasan yang merupakan perasaan campuran yang berisikan ketakutan dan keprihatinan mengenai masa mendatang tanpa sebab khusus. (Gaol, 2018) 
JOURNAL OF PUBLIC HEALTH INNOVATION

Penelitian tersebut diatas sesuai dengan penelitian tentang tingkat kecemasan dengan prestasi kerja terdapat hubungan yang signifikan yaitu semakin tinggi kecemasan maka semakin rendah prestasi kerja karyawan.

Pandemi covid 19 secara cepat dan luas mengakibat perubahan pada segala aspek kehidupan masyarakat dan rasa ketakutan, kecemasan dan kepanikan secara cepat bukan hanya saja di daerah dan di Indonesia bahkan dirasakan dampaknya ke seluruh dunia.

Dari data yang ada jumlah penderita di wilayah Kecamatan Sumber pada bulan juli tahun 2020 diantaranya sebanyak Positif 3 orang, Orang Tanpa Gejala (OTG) 3 orang, Orang Dalam Pemantauan 14 orang, Orang Dalam Resiko (ODR) 612 orang. (Elisabeth, 2017). Penelitian ini bertujuan mengetahui gambaran kecemasan pada pekerja layanan jasa boga di Kabupaten Cirebon Pada Era Pandemi Covid 19 Tahun 2020, adapun hipotesis yang didapatkan ada pengaruh terapi Murottal al-Quran terhadap kecemasan pada pekerja layanan jasa boga di Kabupaten
Cirebon Pada Era Pandemi Covid 19 Tahun 2020.

\section{Metode}

Penelitian ini penelitian kuantitatif yang menggunakan quasi experimental dan rancangan pre and post test with control group design yaitu studi eksperimental yang dalam mengontrol situasi penelitian menggunakan cara non-randomisasi dan pengaruh perlakuan ditentukan dengan membandingkan perubahan nilai-nilai variabel hasil pada kelompok perlakuan dengan perubahan nilai-nilai pada kelompokkontrol. (Murti, 2016)

Kelompok kasus dan kontrol terlebih dahulu diberi tes awal (pre test), kemudian kelompok kasus diberi pengetahuan al-Quran, selanjutnya diberikan perlakuan khusus yaitu mendengarkan terapi Murottal alQuran, setelah diberi perlakuan mendengarkan terapi Murottal al-Quran dilakukan tes kembali sebagai tes akhir (post test), sedangkan untuk kelompok kontrol langsung dilakukan post test tanpa diberikan perlakuan khusus, kemudian dilakukan perbandingan antara kelompok kasus dan kelompok kontrol. 


\section{Hasil (Results)}

Hasil Univariat ada 60 responden disajikan dalam tabel berikut :

Tabel 1.1 Karakteristik responden dan analisis univariat

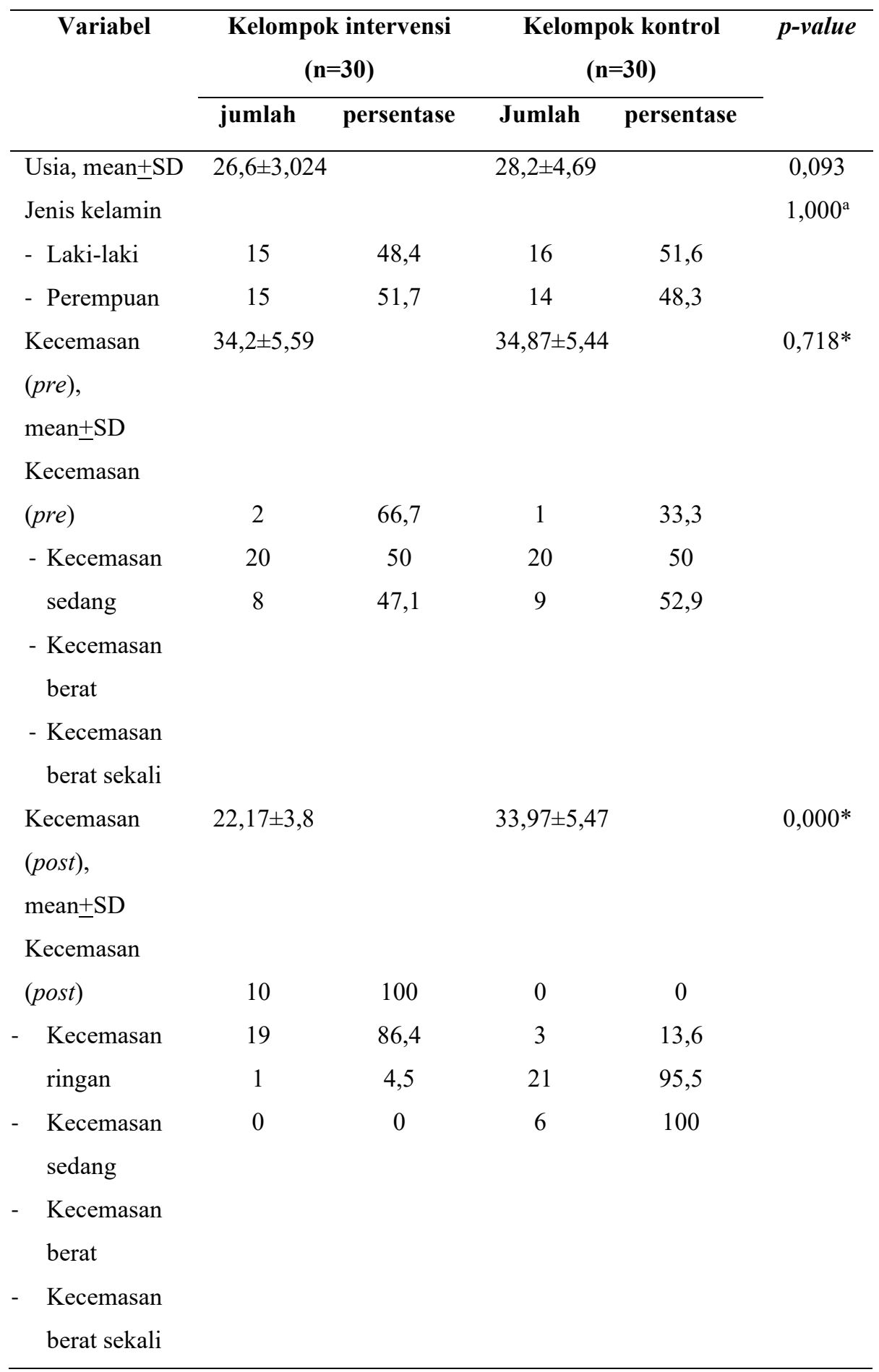


Pekerja dengan kecemasan berat jumlahnya sama pada kedua kelompok sebanyak 20 orang. Pekerja dengan kecemasan berat sekali sebanyak 8 orang $(47,1 \%)$ pada kelompok intervensi dan 9 orang (52,9\%) kelompok kontrol. Hasil Analisis Bivariat Uji beda dua perlakuan menggunakan uji Wilcoxon dengan distribusi sebagai berikut :

Tabel 1.2 Uji Beda Rata-Rata Dua Kelompok Perlakuan

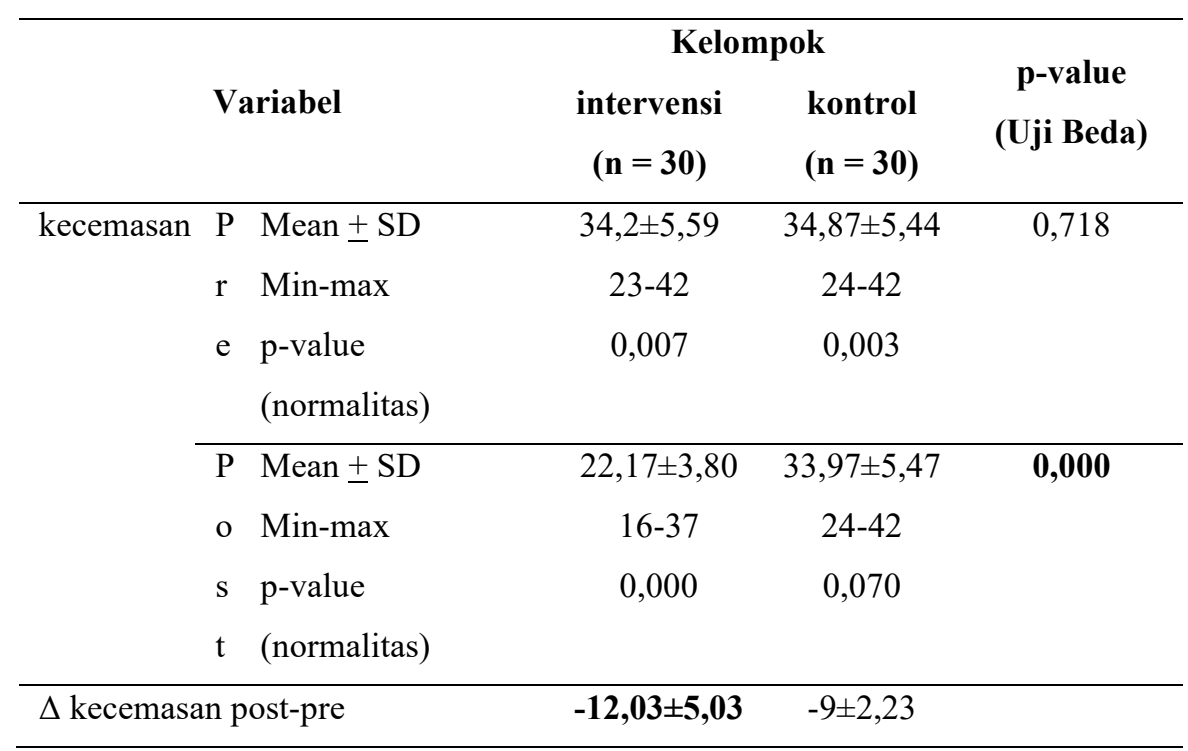

Pada variabel kecemasan, analisis sebelum intervensi tidak berbeda signifikan $(\mathrm{p}$ value $=0,718)$, sedangkan setelah intervensi didapatkan adanya perbedaan yang signifikan $(\mathrm{p}$ value $=0,001)$. Artinya bahwa ada perbedaan skor kecemasan setelah dilakukan intervensi diakibatkan dari adanya perlakuan yang diberikan. Rerata penurunan skor kecemasan pada kelompok intervensi lebih banyak $(-12,03+5,03)$ jika dibandingkan dengan kelompok kontrol $(-9+2,23)$.

\section{Pembahasan}

Berdasarkan hasil wawancara para responden dan dilakukan penelitian didapatkan mayoritas responden merasa lelah dan mengalami kecemasan berat. Hal ini berkaitan dengan aktivitas kerja yang membutuhkan kesiapan fisik, mental, 
JOURNAL OF PUBLIC HEALTH INNOVATION

tingkat dan kondisi lingkungan kerja yang baik, karena pekerjaan yang sifatnya dilakukan berulang seperti proses pencucian, pengolahan, pemasakan, pengepakan, penyajian, dan pengiriman. Selain itu penyebaran pandemi Covid 19 secara cepat dan luas mengakibat perubahan signifikan pada segala aspek kehidupan masyarakat. Pandemi psikologi Covid 19 telah "menyebarkan" ketakutan, kecemasan dan kepanikan secara cepat hingga seluruh dunia termasuk para pekerja di layanan jasa boga juga merasakan kecemasan akan kehilangan pekerjaannya.

Kecemasan adalah respon psikologis terhadap stres yang mengandung komponen fisiologis dan psikologis, perasaan takut atau tidak tenang yang tidak diketahui sebabnya. Seseorang yang mengalami kecemasan berat cenderung memusatkan perhatian pada hal-hal lain untuk mengurangi kecemasan dan memerlukan banyak pengarahan. (Ummu Aiman, 2016)

Hipotesis penelitian yang kedua tingkat kecemasan yaitu ada pengaruh terapi Murattal al-Quran terhadap kecemasan pekerja. Hipotesis tersebut diterima karena sebelum dilakukan terapi Murottal al-Quran tidak terdapat perbedaan skor kelelahan pada kedua kelompok, namun setelah diberikan terdapat perbedaan yang signifikan antara tingkat kecemasan yang diberikan terapi dengan yang tidak sehingga perbedaan tersebut memang diakibatkan dari adanya perlakuan yang diberikan. Rerata penurunan skor kecemasan pada kelompok intervensi lebih banyak $(-12,03+5,03)$ jika dibandingkan dengan kelompok kontrol $(-9+2,23)$. Hal ini sesuai dengan penelitian penelitian sebelumnya tentang Efek terapi Murattal al-Quran terhadap kecemasan, rasio sFlt-1, PLGF dan sFlt-1/PIGF pada ibu hamil dengan risiko preeklamsia oleh Mamlukah, Terdapat perbedaan rata-rata kecemasan sebesar 5,250 (SD 11,021, CI 95\%: 0,092-10,408, p-0,046), sFlt-1 $\mathrm{p}=0,411$, PIGF $\mathrm{p}=0,002$, rasio sFlt$1 /$ plgf $\mathrm{p}=0,001$. (Mamlukah, 2019)

Kecemasan adalah suatu keadaan patologis yang ditandai oleh perasaan ketakutan disertai tanda somatik pertanda sistem saraf otonom yang hiperaktif. Sedangkan depresi adalah gangguan perasaan atau mood yang disertai komponen psikologi 
JOURNAL OF PUBLIC HEALTH INNOVATION

berupa sedih, susah, tidak ada harapan dan putus asa, dan komponen biologi atau somatik misalnya anoreksia, konstipasi, dan keringat dingin. (Hartiningtiyaswati, 2010)

Penelitian yang dilakukan oleh Dina Mutiah Larasati yang berjudul pengaruh terapi musik terhadap tingkat kecemasan sebelum bertanding pada atlet futsal putri tim Muara Enim United, Hasil penelitian menunjukkan bahwa rerata kelompok perlakuan sebesar 59,75 dengan kategori kecemasan ringan, sedangkan pada kelompok kontrol rerata sebesar 72,25 dengan kategori kecemasan sedang. Hasil analisis uji-t menunjukkan bahwa nilai $\mathrm{p}$ value sebesar $0,003<0,05$, ini berarti ada perbedaan yang signifikan pada terapi musik antara kelompok perlakuan dengan kelompok kontrol terhadap kecemasan sebelum bertanding pemain futsal putri tim Muara Enim United. Penelitian ini disimpulkan bahwa terapi musik dapat berpengaruh dalam menurunkan kecemasan sebelum bertanding pada pemain futsal putri, penelitian ini juga sesuai yaitu terapi mendengarkan musik berpengaruh terhadap kecemasan. (Dina Mutiah Larasati, 2017)

Penelitian ini sejalan dengan Rahayu 2019 bahwa terapi Murottal alQuran terbukti efektif dalam menurunkan kecemasan pada pasien yang mengalami kecemasan. Hal ini dapat dilihat dari kondisi klien dimana setelah diberikan terapi murottal AlQur'an klien tampak lebih tenang. (Rahayu, 2019)

Tidak berbeda dengan penelitian yang dilakukan oleh Wenny Savitri yang berjudul terapi musik dan tingkat kecemasan pasien preoperasi yaitu Kontrol kelompok menunjukkan yang meningkat nilai tingkat kecemasan 0,8 tanpa intervensi musik $(\mathrm{t}=-1503, \mathrm{df}=24, \mathrm{p}$ value $<0,05)$, disini sebagai kelompok intervensi menunjukkan menurun nilai tingkat kecemasan $-5.52(\mathrm{t}=5,081, \mathrm{df}=24, \mathrm{p}$ value $<0,05)$ Sedangkan independent $t$ test results untuk kedua kelompok menunjukkan signifikan perbedaan antara kelompok $(\mathrm{t}=3,373, \mathrm{df}=48, \mathrm{p}$ value $<0,05$ ), Dengan hasil Terapi musik memiliki berpengaruh signifikan dalam mengurangi tingkat kecemasan pra operasi pasien. (Savitri, W., Fidayanti, N. And Subiyanto, 2016) 
JOURNAL OF PUBLIC HEALTH INNOVATION

Penelitian sejalan dengan Sari 2014 dengan menggunakan metode yang digunakan dalam penelitian ini adalah Pre-Experimental Design dengan rancangan one group pretestposttest design. Pengambilan sampel menggunakan teknik purposive sampling. Data yang dikumpul kemudian diolah dan dianalisis menggunakan Paired Sample T test untuk melihat pengaruh terapi murottal terhadap tingkat kecemasan pasien pre operasi. Pada penelitian ini menggunakan 15 orang responden, dengan hasil analisis uji statistik Paired Sample T Test diperoleh nilai $\mathrm{p}$ value adalah 0,000 , dengan demikian $p$ value $<\alpha(0,000<0,05)$ maka Ho ditolak dan Ha diterima. Berdasarkan hasil uji $\mathrm{T}$ menunjukan bahwa ada pengaruh yang signifikan terapi Murottal al-Quran terhadap tingkat kecemasan pasien pre operasi di RSUD Labuang Baji Provinsi Sulawesi Selatan. (Sari, 2014)

Pada penelitian Saleh yang sejalan yaitu pengaruh terapi Murottal al-Quran terhadap tingkat kecemasan pada pasien jantung dengan menggunakan metode Jenis penelitian kuantitatif yang menggunakan rancangan penelitian pre- eksperimental design dengan pendekatan one shot case study teknik sampling menggunakan purposive sampling, jumlah sampel 15 orang. Pengumpulan data menggunakan kuesioner Hospital Anxiety \& Depression Scale (HADS). Analisa data yang digunakan adalah uji nonparametrik Wilcoxon Signed Rank. Hasil: Berdasarkan uji Wilcoxon didapatkan $\mathrm{p}$ value $=0,001 \quad(<0,05)$, artinya ada pengaruh terapi Murottal al-Quran terhadap tingkat kecemasan pada pasien jantung di ruang Alamanda RSUD Ulin Banjarmasin. Kesimpulan: Adanya pengaruh murottal al-qur'an terhadap tingkat kecemasan pada pasien dengan penyakit jantung di ruang Alamanda RSUD Ulin Banjarmasin. (Saleh, 2013)

Penelitian yang sejalan juga dilakukan oleh pemaratri merupakan penelitian kuantitatif dengan rancangan pra eksperimen dan menggunakan desain penelitian one group pre post test design. Penelitian ini dilakukan di ruang Melati II RSUD Dr. Moewardi Surakarta dengan sampel penelitian sebanyak 30 anak usia 9-12 tahun menggunakan teknik purposive sampling. Pengumpulan data penelitian 
JOURNAL OF PUBLIC HEALTH INNOVATION

menggunakan kuesioner kecemasan yang dibuat oleh peneliti mengacu pada kuesioner kecemasan T-MAS dan disesuaikan dengan karakteristik anak yang selanjutnya dianalisis menggunakan paired sample t-test.

Hasil uji paired sample t-test diperoleh signifikan (2-tailed) 0,001 lebih kecil dari P-value 0,05, maka keputusan uji adalah Ho ditolak dan $\mathrm{Ha}$ diterima, sehingga ada terapi Murattal al-Quran terhadap kecemasan hospitalisasi pada anak. terapi Murottal al-Quran mempunyai pengaruh yang signifikan terhadap penurunan kecemasan anak yang mengalami hospitalisasi. Anak yang mengalami kecemasan saat hospitalisasi direkomendasikan diberikan terapi murotal. (Pemaratri, 2018)

Dalam penelitian ini juga sejalan yaitu untuk mengetahui efektivitas terapi Murottal al-Quran dalam menurunkan kecemasan pada orang dengan diabetes mellitus. Penelitian ini merupakan penelitian kuantitatif dengan metode eksperimen yang menggunakan teknik pengumpulan data berupa skala kecemasan. Subjek dalam penelitian kali ini berjumlah 15 orang yang menjalani rawat inap di RSUD dr.H. Slamet Martodirdjo Pamekasan dengan kriteria orang dengan diabetes melitus yang memiliki kecemasan tinggi.

Pemilihan subjek dengan cara memberikan skala kecemasan kepada semua orang yang sedang menjalani rawat inap di RSUD dr.H. Slamet Martodirdjo Pamekasan pada bulan oktober. Hasil dari perhitungan skala lalu dibuat norma kelompok dengan rumus interval untuk mengkategorikan kecemasan yakni tinggi dan rendah. Dari 15 orang yang terpilih menjadi subjek penelitian lalu akan melakukan kegiatan terapi Murottal al-Quran.

Hasil penelitian menunjukkan bahwa terapi Murottal al-Quran efektif dalam menurunkan kecemasan pada orang dengan diabetes melitus. (Imama, 2017)

Penelitian ini tidak sejalan dengan penelitian Renny Elisabeth tentang pengaruh pemberian terapi musik klasik terhadap penurunan tingkat kecemasan pada mahasiswa tingkat akhir dalam menyelesaikan tugas akhir di stikes mitra bunda persada batam tahun 2017, Hasil analisis univariat didapatkan bahwa secara keseluruhan rata-rata tingkat 
JOURNAL OF PUBLIC HEALTH INNOVATION

kecemasan pada kelompok intervensi adalah 40.40 dengan standar deviasi sebesar 7.356, dan rata-rata kecemasan 26.87 dengan standar deviasi 9.403 pada kelompok kontrol.

Hasil analisis univariat didapatkan bahwa secara keseluruhan rata-rata tingkat kecemasan pada kelompok intervensi adalah 37.67 dengan standar deviasi sebesar 6.353, dan rata-rata kecemasan 26.80 dengan standar deviasi 9.420 pada kelompok kontrol.

Hasil analisis uji t-berpasangan pada kelompok intervensi didapatkan bahwa ada perbedaan yang signifikan nilai rata-rata tingkat kecemasan dengan $\alpha<0,05$ ( $\mathrm{p}$ value $=0,000)$ sebelum dan sesudah terapi musik. Hal yang berbeda terjadi pada kelompok kontrol yang menunjukkan tidak ada perbedaan yang signifikan nilai ratarata tingkat kecemasan dengan $\alpha>0,05$ $(\mathrm{p}$ value $=0.546)$ antara pre dan post test nilai kecemasan. (Elisabeth, 2017)

\section{Kesimpulan}

Berdasarkan hasil penelitian yang dilakukan maka penulis dapat mengambil kesimpulan bahwa responden mengalami kecemasan berat $(66,6 \%)$, pada pekerja layanan jasa boga di Kabupaten Cirebon Pada Era Pandemi Covid 19 Tahun 2020.

\section{Saran}

Berdasarkan hasil penelitian, pembahasan dan kesimpulan dapat dibuat beberapa saran sebagai berikut :

1. Penelitian selanjutnya

a. Penelitian dapat menggunakan metode lain kecemasan kerja.

b. Peneliti menggunakan jumlah sampel yang lebih banyak, dan menambahkan variabel penelitian,

2. Perusahaan lainnya

Agar dapat menerapkan perlakuan yang sama untuk meminimalisir pada pekerja.

3. Disnakertrans

Agar menjadi pertimbangan kebijakan dalam standar operasional sebelum dimulainya pekerjaan di perusahaan.

\section{Daftar Pustaka}

Dina Mutiah Larasati. (2017). 'Pengaruh Terapi Musik Terhadap Tingkat Kecemasan Sebelum Bertanding Pada Atlet Futsal Putri Tim Muaraenim Unyted.' Jurnal Sains Dan Seni Its, 6(1), P. 11. 
JOURNAL OF PUBLIC HEALTH INNOVATION

Elisabeth, R. (2017). Pengaruh Pemberian Terapi Musik Klasik Terhadap Penurunan Tingkat Kecemasan Pada Mahasiswa Tingkat Akhir Dalam Menyelesaikan Tugas Akhir Di Stikes Mitra Bunda Persada Batam Tahun 2017'. Sumber, U. P. Data Kasus Covid 19 Juli 2020. Cirebon., Pp. 2330.

Gaol, M. J. L. (2018). 'Analisis Faktor Risiko Kelelahan Kerja Pada Karyawan Bagian Produksi Pt. Arwana Anugerah Keramik, Tbk.' Jurnal Ilmu Kesehatan Masyarakat, 9(1)(Doi: 10.26553/Jikm.2018.9.1.5363.), Pp. 53-63.

Hartiningtiyaswati, S. (2010). Hubungan Perilaku Pantang Makanan dengan Lama Penyembuhan Luka Perineum pada Ibu Nifas Di Kecamatan Srengat Kabupaten Blitar.

Imama, I. (2017). Efektivitas Terapi Murattal Al-Qur'an Dalam Menurunkan Kecemasan Pada Orang Dengan Diabetes Melitus Tipe 11. Islam Negeri Sunan Ampel Surabaya.

Mamlukah, M. E. Al. (2019). 'Therapeutic
Effect Of Al-Quran Murattal On Anxiety, Sflt-1, Pigf And Sflt-1/Pigf Ratio In Pregnant Women With Risk Of Preeclampsia.' International Journal Of Research In Medical Sciences, 7(5)(Doi: 10.18203/23206012.Ijrms20191628.), P. 1425.

Murti, B. (2016). Prinsip dan Metode Riset Epidemiologi (Issue 4th edn). Karanganyar: Bintang Fajar Offset.

Pemaratri. (2018). Pengaruh Terapi Murotal Terhadap Kecemasan Hospitalisasi Pada Anak Di Rsud Dr. Moewardi Surakarta.

Rahayu, R. P. P. (2019). 'Efektivitas Terapi Murottal Al-Quran Terhadap Kecemasan Anak Dengan Leukemia "Literature Review." (Jkg) Jurnal Keperawatan Global, 4(2)(Doi: 10.37341/Jkg.V4i2.69.), Pp. 109-114.

Saleh, M. C. I. E. A. (2013). 'Pengaruh Murottal Al-Qur'an Terhadap Tingkat Kecemasan Pada Pasien Jantung.' Perpustakaan Nasional Katalog Dalam Terbitan (Kdt), 001(21(Doi: 10.1007/S00423-006-0143-4.), P. 148. 
Journal of Public HeAlth InNOVATION VOL. 01 No. 02 , JUNI 2021

DOI: $10.34305 /$ JPHI.V1I2.306

Sari, S. P. (2014). Pengaruh Terapi Murottal Al-Quran Terhadap Tingkat Kecemasan Pada Pasien Pre Operasi Di Rumah Sakit Umum Daerah (Rsud) Labuang Baji Provinsi Sulawesi Selatan, Pontificia Universidad Catolica Del Peru.

Savitri, W., Fidayanti, N. And Subiyanto, P. (2016). Terapi Musik Dan Tingkat Kecemasan Pasien Preoperasi'. Media Ilmu Kesehatan, 5(1)(Doi: 10.30989/Mik.V5i1.44.), Pp. 1-6.

Ummu Aiman. (2016). Hubungan Antara Kepercayaan Diri Dengan Kecemasan Pada Mahasiswa Psikologi Semester Vi (Enam) Yang Akan Menghadapi Skripsi'. Journal of Chemical Information And Modeling, 6(2)(Doi: 10.1017/Cbo9781107415324.004.), Pp. 1689-1699. 